\title{
Trends and Prevalence of Overweight and Obesity among Children Aged 2-7 Years from 2011 to 2017 in Xiamen, China
}

\author{
Jing Chen ${ }^{a}$ b Chaoying Hu ${ }^{a}$ Guozhang Zeng ${ }^{a}$ Chao $\mathrm{Xu}^{\mathrm{c}-\mathrm{e}}$ Lijun $\mathrm{Xu}^{\mathrm{a}}$ \\ Junxia Shia Conway Niu ${ }^{f}$ Liangwen Zhang ${ }^{b}$ \\ a Department of Child Health, Women and Children's Hospital, School of Medicine, Xiamen \\ University, Xiamen, China; ${ }^{b}$ School of Public Health, Xiamen University, Xiamen, China; \\ 'Department of Endocrinology, Shandong Provincial Hospital Affiliated to Shandong \\ University, Jinan, China; ${ }^{d}$ Institute of Endocrinology and Metabolism, Shandong Academy \\ of Clinical Medicine, Jinan, China; eShandong Clinical Medical Center of Endocrinology and \\ Metabolism, Jinan, China; ${ }^{f}$ Department of Paediatrics and Child Health, University of Otago, \\ Wellington, New Zealand
}

\section{Keywords}

Children $\cdot$ Chinese $\cdot$ Obesity $\cdot$ Overweight

\begin{abstract}
Background: Childhood overweight and obesity have become some of the most serious public health problems in the 21st century and have a significant impact on affected children as they grow into adulthood. Objective: The purpose of this study was to evaluate the overweight and obesity status and their main influencing factors in preschool children aged 2-7 years in urban areas of China between 2011 and 2017. Methods: A stratified cluster random sampling method was used to conduct a sample survey of children aged 2-7 years in Xiamen, one of China's five special economic zones. The 56,738 participants (29,444 boys, 27,294 girls) were examined at three time points (15,757 in 2011, 19,098 in 2014, and 21,883 in 2017), and were analyzed for factors influencing obesity. Results: Between 2011 and 2017, the prevalence of overweight and obesity in preschool children between 2 and 7 years old was 10.91 and $5.66 \%$, respectively. The overweight and obesity rates were higher in boys ( 11.85 and $7.11 \%)$ than in girls (9.90 and 4.09\%), and the difference was statistically significant ( $p<0.01)$. In the past 7 years, the overweight and obesity rates showed a downward trend in both boys and girls $(p<0.01)$. The peak ages for overweight were 6 years in boys and 2 years in girls, while the obesity rate peaked at 6 years. In those children with obesity, the proportion of those with moderate to severe obesity decreased from $40.70 \%$ in 2011 to $32.80 \%$ in 2017. Multiple stepwise regression analysis showed that children who were averse to sports activities preferred greasy foods and had earlier introduction of solid foods as infants, as well as those who were born at a high birth weight, ate fast, and those with parents with obesity were more likely to
\end{abstract}

Liangwen Zhang, MD, PhD

School of Public Health, Xiamen University

Xiang'an South Road

Xiamen, Fujian 361102 (China)

E-Mail chenjing8469899@126.com
Conway Niu, MBBS

Department of Paediatrics and Child Health

University of Otago

Wellington 6021 (New Zealand)

E-Mail liangwen_zhang @foxmail.com 
have obesity themselves $(p<0.05)$. Conclusions: Although preventative and control measures for childhood obesity have achieved initial results, Chinese preschool children remain to have high levels of overweight and obesity. It is therefore necessary to strengthen monitoring of overweight and obesity in preschool-aged children and implement appropriate interventions when necessary.

(C) 2019 The Author(s)

Published by S. Karger AG, Basel

\section{Introduction}

With increasing standards of living and increasingly urbanized lifestyles, global prevalence of overweight and obesity among children and adolescents has been increasing yearon-year. A 2017 study in The Lancet showed that from 1975 to 2016, the mean body mass index (BMI) of boys and girls aged 5-19 worldwide increased from 16.8 to $17.2 \mathrm{~kg} / \mathrm{m}^{2}$, respectively [1]. Childhood obesity is an increasing worldwide trend, and overweight and obesity among preschool children aged up to 5 years has become an important public health issue of global concern [2]. According to the United Nations International Children's Emergency Fund (UNICEF), the World Health Organisation (WHO), and the World Bank, the number of children with overweight or obesity under 5 years has increased from 32 million in 1990 to 42 million in 2013 [3]. In Africa alone, the number of children with overweight or obesity increased from 4 million to 9 million during the same period [3]. It is expected that by $202511 \%$ of children under 5 will be overweight. Therefore, the WHO has proposed a goal of zero increase in childhood obesity by 2025 [4].

With the rapid development of China's economy and the continuous improvement of living standards, China has had one of the largest increases in the number of people with overweight and obesity globally. The prevalence of childhood overweight and obesity became noticeable around 2000 [5]. In 2002, the rate of overweight and obesity in children and adolescents was $6.6 \%$ and increased to $15.8 \%$ in 2012 . The rate of increase in this decade exceeded the rate of increase in the United States [6, 7]. The Children's Physical Development Survey Collaboration Team, led by the Department of Maternal and Child Health of the National Health and Wellness Committee of China, conducted an epidemiological survey on obesity in children under 7 years old from the northern (Beijing, Harbin, Xi'an), central (Shanghai, Nanjing, Wuhan), and southern (Guangzhou, Fuzhou and Kunming) regions of China between 1986 and 2016. Data were collected in 10-year intervals, with the same methods used at each time point to ensure consistency. During the 30 years during which data were collected, childhood obesity increased rapidly from $0.91 \%$ in 1986 to $3.19 \%$ in 2006 and continued to climb to $4.2 \%$ in 2016 [8]. In the past 30 years, the prevalence of obesity among preschool children under 7 years in China has rapidly increased, and at a rate higher than those of children aged between 5 and 19 years old worldwide [9]. Between 1996 and 2006, the obesity rate spread from the largest metropolises of Beijing and Shanghai to other major cities such as Harbin, Nanjing, and Fuzhou. Between 2006 and 2016, the obesity rate spread further from urban centers to suburban regions, suggesting that the growth trend of childhood obesity in China is still grim [8].

Overweight and obesity not only have serious physical and psychological effects during childhood, but also increase the risk of chronic diseases in adulthood, including hypertension and diabetes $[10,11]$. This highlights the importance of ensuring appropriate monitoring of childhood obesity and emphasizes the importance of primary prevention as an important public health issue in China.

This study took place in Xiamen, a city designated as a special economic zone in China and located on the country's southeast coast. Beginning in 2012, the Ministries of Education, 
Chen et al.: Trends and Prevalence of Overweight and Obesity

Table 1. Sample size of each age and sex group by year of evaluation

\begin{tabular}{|c|c|c|c|c|c|c|c|c|c|c|}
\hline & \multicolumn{3}{|l|}{2011} & \multicolumn{3}{|l|}{2014} & \multicolumn{3}{|l|}{2017} & \multirow[t]{2}{*}{ Total } \\
\hline & boys & girls & total & boys & girls & total & boys & girls & total & \\
\hline \multicolumn{11}{|c|}{ Age, years } \\
\hline 2 & 1,740 & 1,400 & 3,140 & 1,505 & 2,170 & 3,675 & 1,650 & 2,550 & 4,200 & 11,015 \\
\hline 3 & 1,666 & 1,480 & 3,146 & 1,762 & 1,512 & 3,274 & 2,304 & 2,094 & 4,398 & 10,818 \\
\hline 4 & 1,581 & 1,416 & 2,997 & 1,983 & 1,945 & 3,928 & 2,528 & 2,151 & 4,679 & 11,604 \\
\hline 5 & 1,697 & 1,409 & 3,106 & 2,207 & 1,869 & 4,076 & 2,349 & 1,921 & 4,270 & 11,452 \\
\hline $6-7$ & 1,876 & 1,492 & 3,368 & 2,268 & 1,877 & 4,145 & 2,328 & 2,008 & 4,336 & 11,849 \\
\hline Total & 8,560 & 7,197 & 15,757 & 9,725 & 9,373 & 19,098 & 11,159 & 10,724 & 21,883 & 56,738 \\
\hline
\end{tabular}

Health, and Maternal and Child Health introduced guidelines pertaining to the prevention and control of childhood obesity through issuance of the "Technical Specifications for the Management of Childhood Nutritional Diseases" and the "Code of Health Care for Nursery Schools." These guidelines were focused on preschool-aged children and encompassed health education, nutritional awareness, and exercise promotion and were promoted in nurseries and community settings. The municipal authorities also made use of innovative means of health promotion, including a social media presence on WeChat and a purpose-designed app focused on maternal and child health, as well as encouraging greater communication between schools, parents, and community partners.

Despite the aforementioned policies, no studies on childhood overnutrition have been conducted in Xiamen in recent years. In this study, we aimed to continuously monitor overweight and obesity in children aged from 2 to 7 in Xiamen from 2011 to 2017, in order to understand the development and trends in overweight and obesity in preschool-aged children during this 7-year period, and to provide evidence for prevention and control of childhood obesity.

\section{Materials and Methods}

\section{Subjects and Sampling}

This study was a cross-sectional survey of anthropometric measurements in preschool children between 2 and 7 years of age. Data were collected at three time points: 2011, 2014, and 2017. Cluster random sampling and stratified sampling methods were used to select children between 2 and 7 years of age from April 1 to June 30 during each study year. The participants were selected from 40 kindergartens in Xiamen. Children without a signed consent form and those with serious illnesses during the study period were excluded from the study. The participants in the final sample were distributed as follows: 15,757 in 2011 (8,560 boys, 54.33\%), 19,098 in 2014 (9,725 boys, 50.92\%), and 21,883 in 2017 (11,159 boys, $50.99 \%)$. The total sample consisted of 56,738 participants $(29,444$ boys, $51.89 \%$; Table 1). The study was approved by the Human Research Ethics Committee of Xiamen Maternal and Child Health Care Hospital (KY-2016002).

\section{Anthropometry}

Height and weight were measured by the same research staff who had undergone identical training in order to minimize measurement bias. Height was measured using a standard calibrated board ( $0.1 \mathrm{~cm}$; Jiangsu Nantong Weighing Apparatus Factory, Nantong, China), and 
Chen et al:: Trends and Prevalence of Overweight and Obesity

a standard calibrated balance scale $(0.1 \mathrm{~kg}$; Bailida electronic scale; Shanghai Instrument Technology Company, Shanghai, China) was used for obtaining weight. Weight was measured with the participant wearing light clothes and without shoes. Height was measured with shoes off, feet together, and head in the horizontal plane. BMI was calculated using weight and height $\left(\mathrm{kg} / \mathrm{m}^{2}\right)$ measurements.

\section{Diagnostic Criteria}

Nutritional status was determined using cut-offs suggested by the WHO [12]. Diagnostic standards of overweight and obesity were defined as follows according to the 2006 WHO Child Growth Standards: (1) overweight: BMI-for-age $\geq$ P85 and $<$ P95; and (2) obesity: BMIfor-age $\geq$ P95 $[13,14]$. Weight-for-height was calculated using the method developed by the US National Center for Health Statistics and the Centers for Disease Control [15]: Weight-forheight $>$ Reference population weight (for sex and height): 20-29\% was defined as mild obesity, $30-49 \%$ as moderate obesity, and $>50 \%$ as severe obesity.

\section{Grouping}

Using a paired case-control study, children diagnosed with moderate to severe obesity were selected as the case group and matched with healthy children from the same nursery for sex, age (with age difference no greater than 6 months), height (with height difference no greater than $5 \mathrm{~cm}$ ) and selected using a random number table to be paired as a control group. The obesity questionnaire was then administered to the two groups of children.

\section{Questionnaire}

The survey was divided into four parts: (1) family factors such as parental education (0: primary and below, 1: junior high school, 2: high school, 3: undergraduate, 4: master's degree and above); monthly income ( 0 : less than 5,000 yuan, 1: 5,000-10,000 yuan, 2: 10,000-25,000 yuan, 3: more than 25,000 yuan); (2) parental health factors including parental BMI (0: normal, 1 : overweight [ $\left.24 \leq \mathrm{BMI}<28 \mathrm{~kg} / \mathrm{m}^{2}\right], 2$ : obesity [BMI $\left.\geq 28 \mathrm{~kg} / \mathrm{m}^{2}\right]$ ); parental diabetes (0: no, 1: yes), parental hypertension (0: no, 1: yes), parental coronary heart disease (0: no, 1: yes); (3) birth weight and feeding: birth weight (0: less than 2,500 g, 1: 2,500-4,000 g, 2: $4,000 \mathrm{~g}$ or greater), feeding during infancy (0: breastfed, 1 : breastfed mixed with formula feeding, 2: formula fed), time at which solids were introduced ( 0 : before $4 \mathrm{~m}, 1: 4-6 \mathrm{~m}, 2$ : after $6 \mathrm{~m}$ ); (4) behavior and lifestyle factors such as excessive food intake (0: no, 1: yes), eating speed (0: less than $10 \mathrm{~min}, 1: 10-19 \mathrm{~min}, 2: 20-29 \mathrm{~min}, 3: 30 \mathrm{~min}$ or more), preference for greasy food (0: no, 1: yes), preference to eat sweets (0: no, 1: yes), duration of sleep (0: $\leq 8 \mathrm{~h} /$ day, 1: 9-10 h/day, 2: $>10 \mathrm{~h} /$ day), time spent watching television $(0: \leq 59 \mathrm{~min} /$ day, $1: 60-119$ $\mathrm{min} /$ day, $2: \geq 120 \mathrm{~min} /$ day), preference for sports activities (0: no, 1: yes).

From the above, in children aged 2-7, daily intake of carbohydrates exceeding 150, 200, $250,300,350$, or $400 \mathrm{~g}$ for each age, respectively, was considered to be excessive. Fast eating was defined as spending less than $10 \mathrm{~min}$ to finish a meal. A preference for greasy food was defined as eating fried foods or fatty meats more than 7 times per week; preference for sweets was defined as eating sweets more than 3 times a day. Excessive television viewing was defined as spending more than $2 \mathrm{~h}$ watching television daily.

\section{Statistical Analyses}

The prevalence of overweight and obesity was determined in relation to age and sex. Overweight and obesity rates were compared between groups using the $\chi^{2}$ test. Differences in the prevalence of overnutritional outcomes across the years were examined using the $\chi^{2}$ test. At the level of $\alpha=0.05$, the relationship between risk factors for overweight and obesity in preschool children was analyzed by unconditional single factor logistic regression. Multiple 


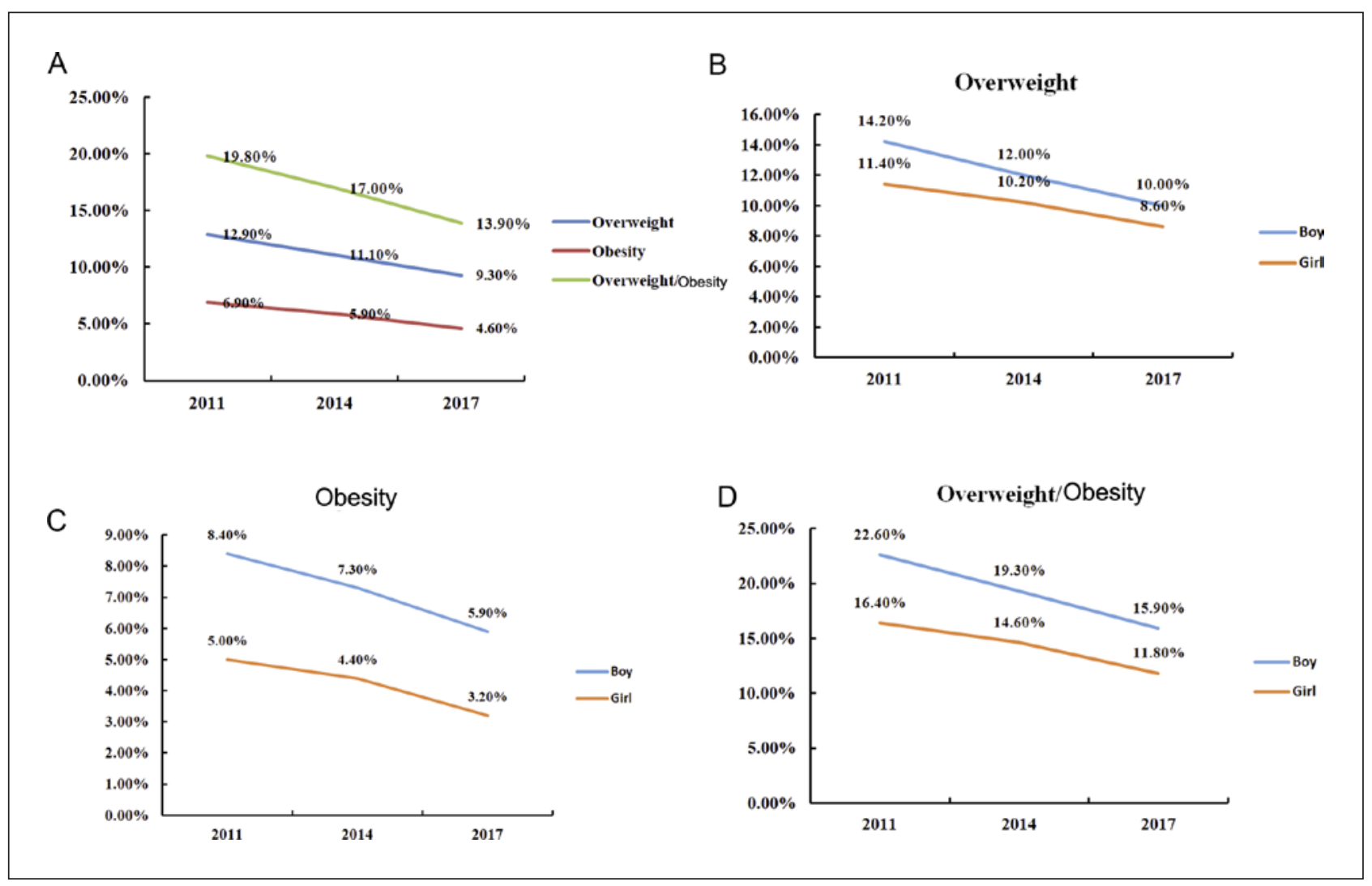

Fig. 1. A Prevalence of overweight/obesity among children aged 2-7 years in 2011-2017. B Prevalence of overweight by sex group among children aged 2-7 years in 2011-2017. C Prevalence of obesity by sex group among children aged 2-7 years in 2011-2017. D Prevalence of overweight/obesity by sex group among children aged 2-7 years in 2011-2017.

stepwise regression analysis was performed on statistically significant factors after single factor logistic regression analysis, controlling for background variables (age, gender, and region). SPSS version 16.0 (SPSS Inc., Chicago, IL, USA) was used for all analyses. $p<0.05$ was considered statistically significant for all analyses.

\section{Results}

\section{An Overview of Childhood Overweight and Obesity}

In 2011, 2014, and 2017, a total of 6,191 preschool children in Xiamen were found to be overweight, with an overall overweight rate of $10.91 \%$. The number of overweight children at the three time points was 2,034,2,117, and 2,040, respectively. The overweight rate was $12.91,11.08$, and $9.32 \%$ at the three time points. The overall overweight rate of boys was $11.85 \%$, with rates and individual time points being 14.17, 11.97, and 9.97\% in 2011, 2014, and 2017, respectively. The overall overweight rate of girls was $9.90 \%$, of which $11.40,10.17$, and $8.64 \%$ were in 2011,2014 , and 2017 , respectively.

In 2011,2014, and 2017, a total of 3,210 preschool children with obesity were found in Xiamen. The overall obesity rate was $5.66 \%$. The number of children with obesity at the three time points was $1,081,1,126$, and 1,003 , respectively. The obesity rate was $6.86,5.90$, and 
Fig. 2. A Prevalence of overweight by sex and age groups among children aged 2-7 years. B Prevalence of obesity by sex and age groups among children aged 2-7 years.

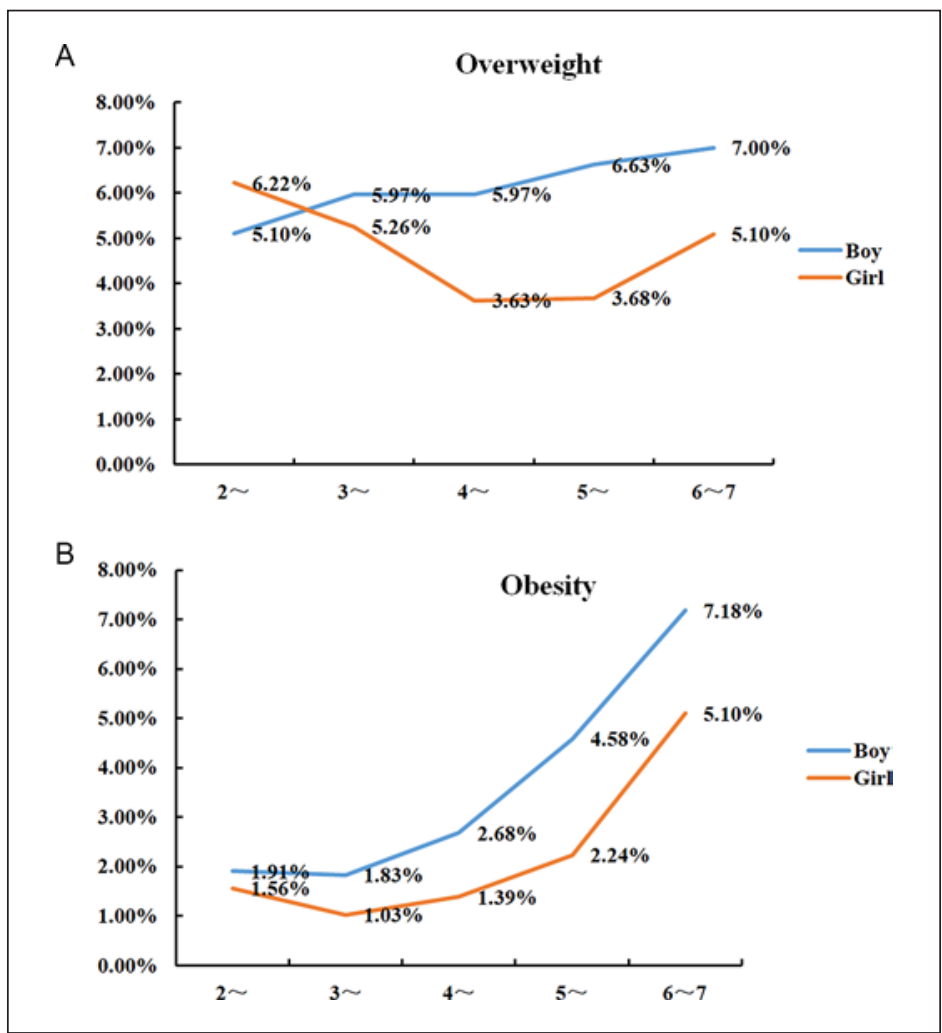

$4.58 \%$. The overall obesity rate of boys was $7.11 \%$, of which $8.43,7.31$, and $5.92 \%$ were found in 2011,2014 , and 2017 , respectively. The overall obesity rate of girls was $4.09 \%$, of which $4.99,4.43$, and $3.19 \%$ were found in 2011,2014 , and 2017, respectively.

The overweight and obesity rates of boys were higher than those of girls, and the difference was statistically significant $(p<0.01)$. In 2011, 2014, and 2017, the rate of overweight and obesity decreased from one time point to the next, and the overweight rate was higher than that of obesity. The trend in overweight and obesity in different years was statistically significant $(p<0.01)$ (Fig. 1).

\section{Trends in Childhood Overweight and Obesity}

The overweight rate of boys increased rapidly at first and gradually afterwards, with the overweight rate peaking in the 6- to 7-year-old group. The overweight rate in girls also increased rapidly at first but then dipped before increasing gradually. The overweight rate peaked in the 2-year-old group in girls. The obesity rate in both boys and girls decreased first and then gradually increased with age. The highest obesity rates in both boys and girls were in the 6- to 7-year-old group, with the difference between each age group statistically significant $(p<0.01)$. With the exception of the overweight rate of girls in the 2-year-old group being higher than boys, the overweight and obesity rates in boys were higher than those of girls, with statistically significant difference $(p<0.01)$ (Fig. 2).

Table 2 shows that the overweight rate of boys in all age groups was statistically significant $(p<0.01)$. At the same time, the overweight rate of girls of different age groups was also statistically significant $(p<0.01)$.

Table 3 shows significant differences in the obesity rates between boys and girls of different age groups $(p<0.01)$. 
Table 2. Prevalence of overweight by sex and age groups among children aged 2-7 years

\begin{tabular}{|c|c|c|c|c|c|c|c|c|c|}
\hline & \multicolumn{3}{|l|}{2011} & \multicolumn{3}{|l|}{2014} & \multicolumn{3}{|l|}{2017} \\
\hline & boys & girls & total & boys & girls & total & boys & girls & total \\
\hline \multicolumn{10}{|c|}{ Age, years } \\
\hline 2 & $\begin{array}{l}219 \\
(12.58)\end{array}$ & $\begin{array}{l}181 \\
(12.93)\end{array}$ & $\begin{array}{l}400 \\
(12.74)\end{array}$ & $\begin{array}{l}175 \\
(11.63)\end{array}$ & $\begin{array}{l}280 \\
(12.90)\end{array}$ & $\begin{array}{l}455 \\
(12.38)\end{array}$ & $\begin{array}{l}168 \\
(10.18)\end{array}$ & $\begin{array}{l}224 \\
(8.78)\end{array}$ & $\begin{array}{l}392 \\
(9.33)\end{array}$ \\
\hline 3 & $\begin{array}{l}237 \\
(14.23)\end{array}$ & $\begin{array}{l}184 \\
(12.43)\end{array}$ & $\begin{array}{l}421 \\
(13.38)\end{array}$ & $\begin{array}{l}218 \\
(12.37)\end{array}$ & $\begin{array}{l}169 \\
(11.18)\end{array}$ & $\begin{array}{l}387 \\
(11.82)\end{array}$ & $\begin{array}{l}191 \\
(8.29)\end{array}$ & $\begin{array}{l}216 \\
(10.32)\end{array}$ & $\begin{array}{l}407 \\
(9.25)\end{array}$ \\
\hline 4 & $\begin{array}{l}232 \\
(14.67)\end{array}$ & $\begin{array}{l}127 \\
(8.97)\end{array}$ & $\begin{array}{l}359 \\
(11.98)\end{array}$ & $\begin{array}{l}216 \\
(10.89)\end{array}$ & $\begin{array}{l}126 \\
(6.48)\end{array}$ & $\begin{array}{l}342 \\
(8.71)\end{array}$ & $\begin{array}{l}245 \\
(9.69)\end{array}$ & $\begin{array}{l}168 \\
(7.81)\end{array}$ & $\begin{array}{l}413 \\
(8.83)\end{array}$ \\
\hline 5 & $\begin{array}{l}251 \\
(14.79)\end{array}$ & $\begin{array}{l}135 \\
(9.58)\end{array}$ & $\begin{array}{l}386 \\
(12.43)\end{array}$ & $\begin{array}{l}278 \\
(12.60)\end{array}$ & $\begin{array}{l}153 \\
(8.19)\end{array}$ & $\begin{array}{l}431 \\
(10.57)\end{array}$ & $\begin{array}{l}230 \\
(9.79)\end{array}$ & $\begin{array}{l}134 \\
(6.98)\end{array}$ & $\begin{array}{l}364 \\
(8.52)\end{array}$ \\
\hline $6-7$ & $\begin{array}{l}274 \\
(14.61)\end{array}$ & $\begin{array}{l}194 \\
(13.00)\end{array}$ & $\begin{array}{l}468 \\
(13.89)\end{array}$ & $\begin{array}{l}277 \\
(12.21)\end{array}$ & $\begin{array}{l}225 \\
(11.99)\end{array}$ & $\begin{array}{l}502 \\
(12.11)\end{array}$ & $\begin{array}{l}279 \\
(11.98)\end{array}$ & $\begin{array}{l}185 \\
(9.21)\end{array}$ & $\begin{array}{l}464 \\
(10.70)\end{array}$ \\
\hline$\overline{\chi^{2}}$ & 4.75 & 21.48 & 6.57 & 19.36 & 54.81 & 58.44 & 16.97 & 75.14 & 78.45 \\
\hline$p$ value & 0.314 & 0.00 & 0.16 & 0.00 & 0.00 & 0.00 & 0.00 & 0.00 & 0.00 \\
\hline
\end{tabular}

Data are presented as $n(\%)$.

Table 3. Prevalence of obesity by sex and age groups among children aged 2-7 years

\begin{tabular}{|c|c|c|c|c|c|c|c|c|c|}
\hline & \multicolumn{3}{|l|}{2011} & \multicolumn{3}{|l|}{2014} & \multicolumn{3}{|l|}{2017} \\
\hline & boys & girls & total & boys & girls & total & boys & girls & total \\
\hline \multicolumn{10}{|c|}{ Age, years } \\
\hline 2 & $\begin{array}{l}80 \\
(4.60)\end{array}$ & $\begin{array}{l}45 \\
(3.21)\end{array}$ & $\begin{array}{l}125 \\
(3.98)\end{array}$ & $\begin{array}{l}63 \\
(4.18)\end{array}$ & $\begin{array}{l}63 \\
(2.90)\end{array}$ & $\begin{array}{l}126 \\
(3.43)\end{array}$ & $\begin{array}{l}66 \\
(4.00)\end{array}$ & $\begin{array}{l}64 \\
(2.50)\end{array}$ & $\begin{array}{l}130 \\
(3.10)\end{array}$ \\
\hline 3 & $\begin{array}{l}58 \\
(3.48)\end{array}$ & $\begin{array}{l}30 \\
(2.03)\end{array}$ & $\begin{array}{l}88 \\
(2.80)\end{array}$ & $\begin{array}{l}62 \\
(3.51)\end{array}$ & $\begin{array}{l}35 \\
(2.31)\end{array}$ & $\begin{array}{l}97 \\
(2.96)\end{array}$ & $\begin{array}{l}78 \\
(3.39)\end{array}$ & $\begin{array}{l}46 \\
(2.20)\end{array}$ & $\begin{array}{l}124 \\
(2.82)\end{array}$ \\
\hline 4 & $\begin{array}{l}108 \\
(6.83)\end{array}$ & $\begin{array}{l}69 \\
(4.87)\end{array}$ & $\begin{array}{l}177 \\
(5.91)\end{array}$ & $\begin{array}{l}99 \\
(4.99)\end{array}$ & $\begin{array}{l}47 \\
(2.42)\end{array}$ & $\begin{array}{l}146 \\
(3.71)\end{array}$ & $\begin{array}{l}104 \\
(4.11)\end{array}$ & $\begin{array}{l}45 \\
(2.09)\end{array}$ & $\begin{array}{l}149 \\
(3.18)\end{array}$ \\
\hline 5 & $\begin{array}{l}176 \\
(10.37)\end{array}$ & $\begin{array}{l}93 \\
(6.60)\end{array}$ & $\begin{array}{l}269 \\
(8.66)\end{array}$ & $\begin{array}{l}185 \\
(8.38)\end{array}$ & $\begin{array}{l}103 \\
(5.51)\end{array}$ & $\begin{array}{l}288 \\
(7.07)\end{array}$ & $\begin{array}{l}164 \\
(6.98)\end{array}$ & $\begin{array}{l}60 \\
(3.12)\end{array}$ & $\begin{array}{l}224 \\
(5.25)\end{array}$ \\
\hline $6-7$ & $\begin{array}{l}300 \\
(15.99)\end{array}$ & $\begin{array}{l}122 \\
(8.18)\end{array}$ & $\begin{array}{l}422 \\
(12.53)\end{array}$ & $\begin{array}{l}302 \\
(13.32)\end{array}$ & $\begin{array}{l}167 \\
(8.90)\end{array}$ & $\begin{array}{l}469 \\
(11.31)\end{array}$ & $\begin{array}{l}249 \\
(10.70)\end{array}$ & $\begin{array}{l}127 \\
(6.32)\end{array}$ & $\begin{array}{l}376 \\
(8.67)\end{array}$ \\
\hline$\chi^{2}$ & 238.31 & 76.46 & 311.47 & 19.36 & 54.81 & 58.44 & 16.97 & 75.14 & 78.45 \\
\hline$p$ value & 0.00 & 0.00 & 0.00 & 0.00 & 0.00 & 0.00 & 0.00 & 0.00 & 0.00 \\
\hline
\end{tabular}

Data are presented as $n(\%)$.

Trends in Obesity at Different Levels

The prevalence of moderate obesity among preschool children in Xiamen dropped from $2.47 \%$ in 2011 to $1.23 \%$ in 2017 . The prevalence of severe obesity decreased from $0.32 \%$ in 2011 to $0.28 \%$ in 2017 . This study analyzed the severity of childhood obesity according to the proportion of children with moderate to severe obesity, which decreased from $40.70 \%$ in 2011 to $32.80 \%$ in 2017 . The proportion of boys with moderate to severe obesity decreased from $45.57 \%$ in 2011 to $35.40 \%$ in 2017 . The proportion of girls with moderate to severe obesity decreased from $30.91 \%$ in 2011 to $27.78 \%$ in 2017 , indicating that the degree of obesity among preschool children in Xiamen has decreased in the past 7 years (Fig. 3; Table 4). 
Fig. 3. A Prevalence of different levels of obesity among children aged 2-7 years in 2011-2017. B The proportion of children aged 2-7 years with different levels of obesity in 2011-2017.

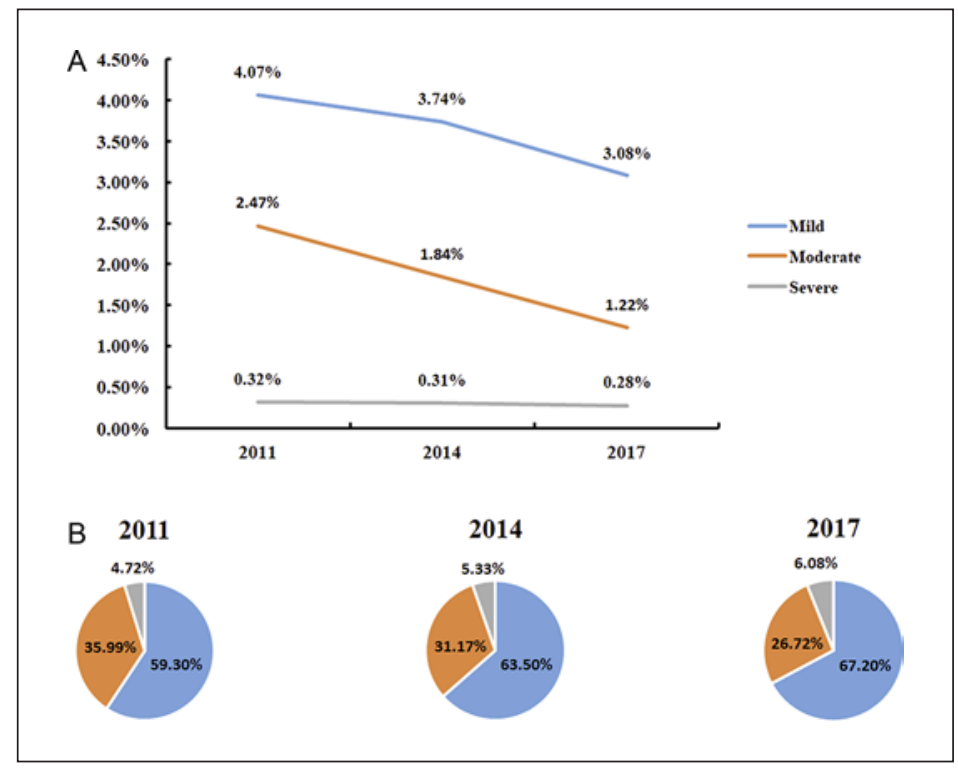

\section{Univariate and Multivariate Analyses of the Causes of Obesity}

Univariate analysis showed that variables that were significant for obesity were high family income, parental obesity, birth weight $\geq 4,000 \mathrm{~g}$, formula feeding in infancy, early introduction of solid food, fast food intake, preference for greasy food, greater time spent watching television, and aversion to exercise $(p<0.05)$. However, there was no statistically significant relationship between obesity and excessive food intake, sugar intake, duration of sleep, parental education levels, and disease factors $(p>0.05)$. Multiple stepwise regression analysis was carried out on 1,180 pairs (828 pairs of boys, 352 pairs of girls) on factors that affect obesity in children aged 2-7 years. Stepwise regression results showed that children with aversion to exercise, preference for greasy foods, or children who had earlier introduction of solid foods, high birth weight, fast eating, and those with obese parents were more likely to have obesity themselves $(p<0.05)$ (Table 5).

\section{Discussion}

The WHO foresaw in 2000 that childhood obesity could become as important a health threat as malnutrition and infectious diseases. In recent years, studies have shown that in some developed countries such as the United States, Australia, the UK, Switzerland, France, and The Netherlands, the upward trend of childhood obesity has slowed or even stabilized [16]. Despite this, there were approximately 41 million children with overweight and obesity under the age of 5 worldwide with increasing rates in low- and middle-income countries, especially in urban areas [17]. The prevalence of overweight and obesity in Chinese children is similar to that seen in most developing countries with economies in transition, with overall rates on the rise [18]. Childhood obesity has become a common public health problem in both developed and developing countries, and implementation of appropriate interventions is of utmost importance.

Because childhood obesity is affected by wide ranging factors, interventions to tackle the issue need to be multifaceted [19-23]. Wang et al. [24] undertook a systematic review of intervention studies in developed countries and found evidence that school-based physical activity interventions with family-based components and school-based dietary and physical 
Table 4. Prevalence of different levels of obesity by sex and age groups among children aged 2-7 years

\begin{tabular}{|c|c|c|c|c|c|c|c|c|c|c|c|c|}
\hline \multirow[t]{2}{*}{ Age } & \multicolumn{4}{|l|}{2011} & \multicolumn{4}{|l|}{2014} & \multicolumn{4}{|l|}{2017} \\
\hline & mild & $\begin{array}{l}\text { mode- } \\
\text { rate }\end{array}$ & severe & $\begin{array}{l}\text { moderate } \\
\text { and severe } \\
\text { obesity, } \%\end{array}$ & mild & $\begin{array}{l}\text { mode- } \\
\text { rate }\end{array}$ & severe & $\begin{array}{l}\text { moderate } \\
\text { and severe } \\
\text { obesity, \% }\end{array}$ & mild & $\begin{array}{l}\text { mode- } \\
\text { rate }\end{array}$ & severe & $\begin{array}{l}\text { moderate } \\
\text { and severe } \\
\text { obesity, \% }\end{array}$ \\
\hline \multicolumn{13}{|c|}{ Boys, years } \\
\hline 2 & $\begin{array}{l}58 \\
(3.33)\end{array}$ & $\begin{array}{l}18 \\
(1.03)\end{array}$ & $\begin{array}{l}4 \\
(0.23)\end{array}$ & 27.50 & $\begin{array}{l}50 \\
(3.32)\end{array}$ & $\begin{array}{l}10 \\
(0.66)\end{array}$ & $\begin{array}{l}3 \\
(0.20)\end{array}$ & 20.63 & $\begin{array}{l}50 \\
(3.03)\end{array}$ & $\begin{array}{l}12 \\
(0.73)\end{array}$ & $\begin{array}{l}4 \\
(0.24)\end{array}$ & 24.24 \\
\hline 3 & $\begin{array}{l}36 \\
(2.16)\end{array}$ & $\begin{array}{l}16 \\
(0.96)\end{array}$ & $\begin{array}{l}6 \\
(0.36)\end{array}$ & 37.93 & $\begin{array}{l}48 \\
(2.72)\end{array}$ & $\begin{array}{l}10 \\
(057)\end{array}$ & $\begin{array}{l}4 \\
(0.23)\end{array}$ & 22.58 & $\begin{array}{l}66 \\
(2.86)\end{array}$ & $\begin{array}{l}8 \\
(0.35)\end{array}$ & $\begin{array}{l}4 \\
(0.17)\end{array}$ & 15.38 \\
\hline 4 & $\begin{array}{l}55 \\
(3.38)\end{array}$ & $\begin{array}{l}46 \\
(2.90)\end{array}$ & $\begin{array}{l}7 \\
(0.44)\end{array}$ & 49.07 & $\begin{array}{l}55 \\
(2.77)\end{array}$ & $\begin{array}{l}39 \\
(1.97)\end{array}$ & $\begin{array}{l}5 \\
(0.25)\end{array}$ & 44.44 & $\begin{array}{l}66 \\
(2.61)\end{array}$ & $\begin{array}{l}31 \\
(1.23)\end{array}$ & $\begin{array}{l}7 \\
(0.28)\end{array}$ & 36.54 \\
\hline 5 & $\begin{array}{l}96 \\
(5.66)\end{array}$ & $\begin{array}{l}70 \\
(4.12)\end{array}$ & $\begin{array}{l}10 \\
(0.59)\end{array}$ & 45.45 & $\begin{array}{l}114 \\
(5.16)\end{array}$ & $\begin{array}{l}63 \\
(2.85)\end{array}$ & $\begin{array}{l}8 \\
(0.36)\end{array}$ & 38.38 & $\begin{array}{l}94 \\
(4.00)\end{array}$ & $\begin{array}{l}62 \\
(2.64)\end{array}$ & $\begin{array}{l}8 \\
(0.34)\end{array}$ & 42.68 \\
\hline $6-7$ & $\begin{array}{l}148 \\
(7.89)\end{array}$ & $\begin{array}{l}142 \\
(7.57)\end{array}$ & $\begin{array}{l}10 \\
(0.53)\end{array}$ & 50.67 & $\begin{array}{l}179 \\
(7.89)\end{array}$ & $\begin{array}{l}99 \\
(4.37)\end{array}$ & $\begin{array}{l}24 \\
(1.06)\end{array}$ & 40.73 & $\begin{array}{l}151 \\
(6.48)\end{array}$ & $\begin{array}{l}78 \\
(3.35)\end{array}$ & $\begin{array}{l}20 \\
(0.86)\end{array}$ & 39.36 \\
\hline Total & $\begin{array}{l}393 \\
(4.59)\end{array}$ & $\begin{array}{l}292 \\
(3.41)\end{array}$ & $\begin{array}{l}37 \\
(0.43)\end{array}$ & 45.57 & $\begin{array}{l}446 \\
(4.58)\end{array}$ & $\begin{array}{l}221 \\
(2.27)\end{array}$ & $\begin{array}{l}44 \\
(0.45)\end{array}$ & 37.27 & $\begin{array}{l}427 \\
(3.83)\end{array}$ & $\begin{array}{l}191 \\
(1.71)\end{array}$ & $\begin{array}{l}43 \\
(0.39)\end{array}$ & 35.40 \\
\hline \multicolumn{13}{|c|}{ Girls, years } \\
\hline 2 & $\begin{array}{l}34 \\
(2.43)\end{array}$ & $\begin{array}{l}8 \\
(0.57)\end{array}$ & $\begin{array}{l}3 \\
(0.21)\end{array}$ & 24.44 & $\begin{array}{l}56 \\
(2.58)\end{array}$ & $\begin{array}{l}5 \\
(0.23)\end{array}$ & $\begin{array}{l}2 \\
(0.09)\end{array}$ & 11.11 & $\begin{array}{l}56 \\
(2.19)\end{array}$ & $\begin{array}{l}6 \\
(0.36)\end{array}$ & $\begin{array}{l}2 \\
(0.08)\end{array}$ & 12.50 \\
\hline 3 & $\begin{array}{l}26 \\
(1.75)\end{array}$ & $\begin{array}{l}4 \\
(0.27)\end{array}$ & $\begin{array}{l}0 \\
(0)\end{array}$ & 13.33 & $\begin{array}{l}24 \\
(1.59)\end{array}$ & $\begin{array}{l}10 \\
(0.66)\end{array}$ & $\begin{array}{l}1 \\
(0.07)\end{array}$ & 31.43 & $\begin{array}{l}34 \\
(1.62)\end{array}$ & $\begin{array}{l}9 \\
(0.39)\end{array}$ & $\begin{array}{l}3 \\
(0.14)\end{array}$ & 26.09 \\
\hline 4 & $\begin{array}{l}45 \\
(3.18)\end{array}$ & $\begin{array}{l}22 \\
(1.55)\end{array}$ & $\begin{array}{l}2 \\
(0.14)\end{array}$ & 34.78 & $\begin{array}{l}31 \\
(1.59)\end{array}$ & $\begin{array}{l}15 \\
(0.77)\end{array}$ & $\begin{array}{l}1 \\
(0.05)\end{array}$ & 34.04 & $\begin{array}{l}35 \\
(1.63)\end{array}$ & $\begin{array}{l}8 \\
(0 . .32)\end{array}$ & $\begin{array}{l}2 \\
(0.09)\end{array}$ & 22.22 \\
\hline 5 & $\begin{array}{l}59 \\
(4.19)\end{array}$ & $\begin{array}{l}29 \\
(2.05)\end{array}$ & $\begin{array}{l}5 \\
(0.35)\end{array}$ & 36.56 & $\begin{array}{l}64 \\
(3.42)\end{array}$ & $\begin{array}{l}33 \\
(1.77)\end{array}$ & $\begin{array}{l}6 \\
(0.32)\end{array}$ & 37.86 & $\begin{array}{l}44 \\
(2.29)\end{array}$ & $\begin{array}{l}16 \\
(0.68)\end{array}$ & $\begin{array}{l}0 \\
(0)\end{array}$ & 26.67 \\
\hline $6-7$ & $\begin{array}{l}84 \\
(5.63)\end{array}$ & $\begin{array}{l}34 \\
(2.27)\end{array}$ & $\begin{array}{l}4 \\
(0.26)\end{array}$ & 31.15 & $\begin{array}{l}94 \\
(5.00)\end{array}$ & $\begin{array}{l}67 \\
(3.57)\end{array}$ & $\begin{array}{l}6 \\
(0.32)\end{array}$ & 43.71 & $\begin{array}{l}78 \\
(3.88)\end{array}$ & $\begin{array}{l}38 \\
(1.63)\end{array}$ & $\begin{array}{l}11 \\
(0.55)\end{array}$ & 38.58 \\
\hline Total & $\begin{array}{l}248 \\
(3.45)\end{array}$ & $\begin{array}{l}97 \\
(1.35)\end{array}$ & $\begin{array}{l}14 \\
(0.19)\end{array}$ & 30.91 & $\begin{array}{l}269 \\
(2.86)\end{array}$ & $\begin{array}{l}130 \\
(1.38)\end{array}$ & $\begin{array}{l}16 \\
(0.17)\end{array}$ & 35.18 & $\begin{array}{l}247 \\
(2.30)\end{array}$ & $\begin{array}{l}77 \\
(0.69)\end{array}$ & $\begin{array}{l}18 \\
(0.17)\end{array}$ & 27.78 \\
\hline
\end{tabular}

Data are presented as $n(\%)$.

Table 5. Multiple stepwise regression analysis of risk factors for obesity among children aged 2-7 years in Xiamen, China

\begin{tabular}{llllllr}
\hline Variables & \multicolumn{1}{l}{ SE } & \multicolumn{1}{l}{ Wald } & df & \multicolumn{1}{l}{ Sig } & $\operatorname{Exp}(B)$ \\
\hline Dislike physical activity & 2.605 & 0.258 & 102.022 & 1 & 0.000 & 13.531 \\
Like greasy food & 2.045 & 0.254 & 64.883 & 1 & 0.000 & 7.731 \\
Add solid food earlier & 1.450 & 0.280 & 26.893 & 1 & 0.000 & 4.263 \\
Birth weight $>4,000 \mathrm{~g}$ & 1.121 & 0.271 & 17.118 & 1 & 0.000 & 3.067 \\
Eating quickly & 0.835 & 0.278 & 9.024 & 1 & 0.003 & 2.304 \\
Obese parents & 0.590 & 0.242 & 5.918 & 1 & 0.015 & 1.803 \\
\hline
\end{tabular}

activity interventions with family- and community-based components were efficacious. Feng et al. [25] systematically reviewed intervention studies in mainland China and found that comprehensive interventions which involved diet and exercise in schools have a better effect on childhood obesity, but reproducible and accessible intervention techniques are still lacking. There are other studies which found that interventions which involved multiple settings had more marked results than those conducted in a single setting [26]. In addition, Nyström et al. [27] found that mobile devices (e.g., smart phones) can enhance the effec- 
tiveness of interventions and at a lower cost. As such, childhood obesity interventions via mobile devices have become popular topics in research.

Relating to this study, the Municipal government of Xiamen adopted a model to tackle obesity in preschool-aged children through a joint management program involving the children's families, schools, and local community groups since 2012. Main areas of this program include: (1) Health education: regular seminars to promote healthy behavior and publication of pamphlets; (2) Exercise: community health doctors and teachers work together to ensure that no less than $2 \mathrm{~h}$ of appropriate physical activities are scheduled in nurseries, with an aim for exercise to increase heart rate to $130-150 \mathrm{bpm}$; (3) Balanced nutrition: recipes are made available weekly to ensure that food provided in nurseries meet $80 \%$ of daily recommended amounts, with parents advised to limit food intake after going home; (4) Feedback is given to parents after each follow-up by community doctors with guidance on food and exercise at home; (5) Mobile health technology: community doctors can utilize maternal and children health care information system set up by the municipal government to broadcast text messages to parents whose children with overweight and obesity to encourage appropriate follow-up. This platform also allows for telephone consultations if necessary. A social media service set up on WeChat also encourages communication between nurseries and parents and sends push messages to parents' devices to promote health, as well as provides recipes for healthy meals.

The results of this study show that the prevalence of overweight and obesity among preschool children aged 2-7 years in Xiamen has decreased between 2011 and 2017. In children with obesity, the proportion of those with moderate to severe obesity decreased from $40.70 \%$ in 2011 to $32.80 \%$ in 2017 . A possible reason for this change is implementation of the aforementioned interventions by the municipal government in recent years. Childhood overweight and obesity can only be improved with the combined efforts of all facets of society. These dietary, exercise-related, and behavioral interventions have achieved promising results. In this study, the steps taken to promote better communication between parents and nurseries via social media platforms may have also influenced outcomes. It is noteworthy, however, that the proportion of severe obesity increased from $4.72 \%$ in 2011 to $6.08 \%$ in 2017. A possible explanation for this is that as the degree of obesity increases, so too does the risk of related complications and the difficulty of treatment. The prevalence of overweight and obesity is higher in boys than in girls, except for girls in the 2-year old group, in which the overweight rate is higher in girls than in boys. Overall, this suggests that the problem of overweight and obesity in preschool children is one that disproportionately affects boys. This may be explained by a number of reasons, including that the mechanism of overweight and obesity in girls may be more complicated, or by social norms, in which girls may be influenced to pay more attention to their physical appearance than boys. Among different age groups, the peak age group for overweight in boys was in the 6- to 7-year-old group, while the peak age group for overweight in girls was in the 2-year-old group. The highest obesity rate for both boys and girls was in the 6- to 7-year-old group. It is worth noting that children in this age group tend to eat more irregularly and tend to eat more carbohydrates, and thus tend to have an insufficient intake of vegetables. Children in this age group are also prone to eating too fast, suggesting that child care institutions and schools should place more emphasis on appropriate nutritional needs of children and the need to establish healthy eating habits. In addition, children at this age have adiposity rebound, with approximately half continuing on this rebound trajectory until adolescence. During this crucial period, the importance of prevention and management of obesity cannot be stressed enough.

This survey suggests that unhealthy lifestyles are closely related to the occurrence of obesity. In the obesity group, the percentage of children who eat too fast, prefer greasy food, watch TV for extended periods of time, and are averse to exercise is significantly higher than in the control group. The reduction of physical activity and outdoor activities, along with 
Chen et al.: Trends and Prevalence of Overweight and Obesity

increased time spent watching TV, using the Internet, playing video games, and studying lead to a sedentary lifestyle, ultimately increasing the risk of childhood obesity [28, 29]. However, the aforementioned studies are often limited to assessing physical activity based on questionnaires, and thus lack necessary precision. This is especially the case in studies involving children. Parental obesity is more common in children with obesity, not only due to genetics, but also from the impact of parental lifestyles on their children, on top of genetic factors which may influence food preferences and appetite [30]. Obesity in preschool children is related to birth weight and feeding patterns in infancy. Formula feeding in infants and early introduction of solid foods are important factors which contribute to childhood obesity. This study shows that children with high birth weights are more likely to suffer from obesity, suggesting that proper nutrition during pregnancy and prevention of excessive birth weight are factors that prevent childhood obesity that should not be overlooked. Obesity is more common in those from high-income families, which suggests that with economic improvements, it is necessary to raise the level of parental knowledge about nutrition. The absence of such measures is likely to further increase the prevalence of childhood obesity.

In summary, China's work to improve children's nutrition and health has made great progress but at the same time faces new challenges. Although the measures for prevention and control of obesity have achieved initial results in Xiamen, further efforts are necessary. Childhood obesity is associated with a variety of factors. This cross-sectional study focused on the changes of obesity trends in recent years after the introduction of obesity intervention measures for preschool children in Xiamen in 2012 and is limited in its ability to prove causation. In the future, longitudinal intervention studies with large samples and matched controls will be needed to evaluate the long-term effects of intervention measures, to provide a basis for the prevention and treatment of childhood obesity.

\section{Acknowledgements}

We are grateful to all study participants. We also thank all investigators for their engagement and relentless efforts in collecting and analyzing the data.

\section{Statement of Ethics}

Written informed consent was obtained from the parents or guardians of the participants to take part in this study. The study protocol was approved by the research institute's committee on human research.

\section{Disclosure Statement}

The authors have no conflicts of interest to declare.

\section{Funding Sources}

This study was supported by a grant from National Natural Science Foundation of China (81370891, 81670720), Xiamen Science and Technology Commission (3502Z20164029), Guiding project of the Natural Science Foundation of Fujian (2019D010), and special funds for Taishan Scholar Project (tsqn20161071). 
Chen et al.: Trends and Prevalence of Overweight and Obesity

\section{Author Contributions}

J.C., C.H., G.Z., L.X., and J.S. supervised the data collection and quality control. J.C. and L.Z. conducted data analyses. L.Z. and C.N. revised the manuscript. C.X. advised the study and critically read the manuscript, and J.C. drafted the manuscript. All authors read and approved the final manuscript.

\section{References}

1 Abarca-Gómez L, Abdeen ZA, Hamid ZA, Abu-Rmeileh NM, Acosta-Cazares B, Acuin C, et al.; NCD Risk Factor Collaboration (NCD-RisC). Worldwide trends in body-mass index, underweight, overweight, and obesity from 1975 to 2016: a pooled analysis of 2416 population-based measurement studies in 128.9 million children, adolescents, and adults. Lancet. 2017 Dec;390(10113):2627-42.

2 Lobstein T, Jackson-Leach R, Moodie ML, Hall KD, Gortmaker SL, Swinburn BA, et al. Child and adolescent obesity: part of a bigger picture. Lancet. 2015 Jun;385(9986):2510-20.

3 Reilly JJ, Kelly J. Long-term impact of overweight and obesity in childhood and adolescence on morbidity and premature mortality in adulthood: systematic review. Int J Obes. 2011 Jul;35(7):891-8.

4 Datar A, Chung PJ. Changes in Socioeconomic, Racial/Ethnic, and Sex Disparities in Childhood Obesity at School Entry in the United States. JAMA Pediatr. 2015 Jul;169(7):696-7.

5 Ji CY, Sun JL, Chen TJ. [Dynamic analysis on the prevalence of obesity and overweight school-age children and adolescents in recent 15 years in China]. Zhonghua Liu Xing Bing Xue Za Zhi. 2004 Feb;25(2):103-8.

6 Ogden CL, Carroll MD, Curtin LR, McDowell MA, Tabak CJ, Flegal KM. Prevalence of overweight and obesity in the United States, 1999-2004. JAMA. 2006 Apr;295(13):1549-55.

7 Ogden CL, Carroll MD, Flegal KM. High body mass index for age among US children and adolescents, 20032006. JAMA. 2008 May;299(20):2401-5.

8 Capital Institute of Pediatrics; Coordinating Study Group of Nine Cities on the Physical Growth and Development of Children. [A national epidemiological survey on obesity of children under seven years of age in nine cities of China in 2016]. Zhonghua Er Ke Za Zhi. 2018 Oct;56(10):745-52.

9 WHO. Tenfold increase in childhood and adolescent obesity in four decades: new study by Imperial College London and WHO. 2017. Available from: https://www.who.int/news-room/detail/11-10-2017-tenfoldincrease-in-childhood-and-adolescent-obesity-in-four-decades-new-study-by-imperial-college-londonand-who

10 Tapp RJ, Venn A, Huynh QL, Raitakari OT, Ukoumunne OC, Dwyer T, et al. Impact of adiposity on cardiac structure in adult life: the Childhood Determinants of Adult Health (CDAH) study. BMC Cardiovasc Disord. 2014 Jul;14(1):79.

11 Kelsey MM, Zaepfel A, Bjornstad P, Nadeau KJ. Age-related consequences of childhood obesity. Gerontology. 2014;60(3):222-8.

12 WHO Multicentre Growth Reference Study Group. WHO Child Growth Standards: Length/Height-for-Age, Weight-for-Age, Weight-for-Length, Weight-for-Height and Body Mass Index-for-Age: Methods and Development. Geneva, Switzerland: WHO; 2006.

13 WHO. World Health Organization Training Course on Child Growth Assessment. Geneva, Switzerland: WHO; 2006.

14 Das MK, Bhattacharyya N, Bhattacharyya AK. WHO child growth standards. Eur J Pediatr. 2010 Feb;169(2): 253-5.

15 National Center for Health Statistics, Centers for Disease Control. Normalized NCHS/CDC anthropometric reference. Atlanta: Centers for Disease Control; 1990. p. 1-100.

16 Olds T, Maher C, Zumin S, Péneau S, Lioret S, Castetbon K, et al. Evidence that the prevalence of childhood overweight is plateauing: data from nine countries. Int J Pediatr Obes. 2011 Oct;6(5-6):342-60.

17 Monteiro PO, Victora CG. Rapid growth in infancy and childhood and obesity in later life-a systematic review. Obes Rev. 2005 May;6(2):143-54.

18 Yu DM, Ju LH, Zhao LY, Fang HY, Yang ZY, Guo HJ, et al. [Prevalence and characteristics of overweight and obesity in Chinese children aged 0-5 years]. Zhonghua Liu Xing Bing Xue Za Zhi. 2018 Jun;39(6):710-4.

19 Bucher Della Torre S, Keller A, Laure Depeyre J, Kruseman M. Sugar-Sweetened Beverages and Obesity Risk in Children and Adolescents: A Systematic Analysis on How Methodological Quality May Influence Conclusions. J Acad Nutr Diet. 2016 Apr;116(4):638-59.

20 Gadiraju TV, Patel Y, Gaziano JM, Djoussé L. Fried Food Consumption and Cardiovascular Health: A Review of Current Evidence. Nutrients. 2015 Oct;7(10):8424-30.

21 Kim K, Ok G, Jeon S, Kang M, Lee S. Sport-based physical activity intervention on body weight in children and adolescents: a meta-analysis. J Sports Sci. 2017 Feb;35(4):369-76.

22 Nago ES, Lachat CK, Dossa RA, Kolsteren PW. Association of out-of-home eating with anthropometric changes: a systematic review of prospective studies. Crit Rev Food Sci Nutr. 2014;54(9):1103-16. 
23 Biddle SJ, García Bengoechea E, Wiesner G. Sedentary behaviour and adiposity in youth: a systematic review of reviews and analysis of causality. Int J Behav Nutr Phys Act. 2017 Mar;14(1):43.

24 Wang Y, Cai L, Wu Y, Wilson RF, Weston C, Fawole O, et al. What childhood obesity prevention programmes work? A systematic review and meta-analysis. Obes Rev. 2015 Jul;16(7):547-65.

25 Feng L, Wei DM, Lin ST, Maddison R, Ni Mhurchu C, Jiang Y, et al. Systematic review and meta-analysis of school-based obesity interventions in mainland China. PLoS One. 2017 Sep;12(9):e0184704.

26 van Sluijs EM, McMinn AM, Griffin SJ. Effectiveness of interventions to promote physical activity in children and adolescents: systematic review of controlled trials. Br J Sports Med. 2008 Aug;42(8):653-7.

27 Nyström CD, Sandin S, Henriksson P, Henriksson H, Trolle-Lagerros Y, Larsson C, et al. Mobile-based intervention intended to stop obesity in preschool-aged children: the MINISTOP randomized controlled trial. Am J Clin Nutr. 2017 Jun;105(6):1327-35.

28 Kilpeläinen TO, Qi L, Brage S, Sharp SJ, Sonestedt E, Demerath E, et al. Physical activity attenuates the influence of FTO variants on obesity risk: a meta-analysis of 218,166 adults and 19,268 children. PLoS Med. 2011 Nov; 8(11):e1001116.

29 Busto-Zapico R, Amigo-Vázquez I, Peña-Suárez E, Fernández-Rodríguez C. Relationships between sleeping habits, sedentary leisure activities and childhood overweight and obesity. Psychol Health Med. 2014;19(6): 667-72.

30 Wells JC, Siervo M. Obesity and energy balance: is the tail wagging the dog? Eur J Clin Nutr. 2011 Nov; 65(11): 1173-89. 